\title{
CFD Analysis of Mixing and Combustion of a Scramjet Combustor with a Planer Strut Injector
}

\author{
K.M.Pandey and T.Sivasakthivel
}

\begin{abstract}
As one of the most promising propulsive systems in the future, the scramjet engine has drawn the attention of many researchers. The two-dimensional coupled implicit NS equations, the standard $k-\varepsilon$ turbulence model and the finite-rate/eddy-dissipation reaction model have been applied to numerically simulate the flow field of the hydrogen fueled scramjet combustor with a planer strut flame holder under two different working conditions, namely, cold flow and engine ignition. The obtained results show that the numerical method used in this paper is suitable to simulate the flow field of the scramjet combustor. The static pressure distribution along the top and bottom walls for the case under the condition of engine ignition is much higher than that for the case under the condition of cold flow. There are three clear pressure rises on the top and bottom walls of the scramjet combustor. The eddy generated in the strut acts as a flame holder in the combustor, and it can prolong the residence time of the mixture in the supersonic flow.
\end{abstract}

Index Terms-Flame holder, $k-\varepsilon$ model, Scramjet and Supersonic combustion.

\section{INTRODUCTION}

The Supersonic Combustion Ramjet (SCRAMJET) engine has been recognized as the most promising air breathing propulsion system for the hypersonic flight (Mach number above 5). In recent years, the research and development of scramjet engine has promoted the study of combustion in supersonic flows. Extensive research is being carried out over the world for realizing the scramjet technology with hydrogen fuel with significant attention focused on new generations of space launchers and global fast-reaction reconnaissance missions. However, application for the scramjet concept using high heat sink and hydrogen fuels offers significantly enhanced mission potential for future military tactical missiles. Scramjet being an air-breathing engine, the performance of the missile system based on the scramjet propulsion is envisaged to enhance the payload weight and missile range. Supersonic combustion ramjet engine for an air-breathing propulsion system has been realized and demonstrated by USA on ground and in flight. $\mathrm{X}-43$ vehicle used hydrogen fuel. Hydrocarbon fuel scramjet engine is still under study and research.

Manuscript received February 25, 2011

K.M.Pandey, Senior Member IACSIT, and Professor

Department of Mechanical Engineering,N.I.T Silchar, Assam, India Email: kmpandey2001@yahoo.com

T.Sivasakthivel, M.Tech - Thermal Engineering, Department of Mechanical Engineering,N.I.T Silchar, Assam, India

Email: sivasakthivel.t@gmail.com
Mixing, ignition and flame holding in combustor, ground test facilities and numerical simulation of Scramjet engine are the critical challenges in the development of scramjet engine.

\section{A. Mixing, Ignition and flame holding in a scramjet combustor}

Among the critical components of the scramjet engine, the combustor presents the most formidable problems. The complex phenomenon of supersonic combustion involves turbulent mixing, shock interaction and heat release in supersonic flow. The flow field within the combustor of scramjet engine is very complex and poses a considerable challenge in design and development of a supersonic combustor with an optimized geometry. Such combustor shall promote sufficient mixing of the fuel and air so that the desired chemical reaction and thus heat release can occur within the residence time of the fuel -air mixture. In order to accomplish this task, it requires a clear understanding of fuel injection processes and thorough knowledge of the processes governing supersonic mixing and combustion as well as the factors, which affects the losses within the combustor. The designer shall keep in mind the following goals namely,

- Good and rapid fuel air mixing

- Minimization of total pressure loss

- High combustion efficiency.

\section{B. Scramjet Fuel Injection system}

Due to the extremely short residence time of the air in supersonic combustors, an efficient (rapid and with small losses in total pressure) fuel/air mixing is hard to achieve. Nevertheless this is an important issue to keep the combustor length short and to reduce the skin friction drag. In supersonic flows a rapid fuel/air mixing additionally suffers from inherently low mixing rates due to compressibility effects at high convective Mach numbers $[16,17]$. There are mainly two concepts for fuel injection in supersonic combustors:

Wall injectors, where hydrogen is injected through the wall [18-20] (normal or oblique to the main flow) or by ramps [21-23] mounted to the wall,

Strut injectors [16, 24-26], which are located at the channel axis and directly inject the fuel into the core of the air stream.

In some cases both types of injectors approach each other, e.g. if a ramp injector extends over most of the channel height [23]. A good near field mixing can be achieved by wall injection. On the other hand transverse injection systems cause a significant blockage of the flow resulting in irreversibility's due to shock waves and thrust losses [27]. Another concern is that the penetration of the fuel jet may be 
insufficient for real size combustors. In wall injectors no losses in total pressure if they are switched off. The last point is in contrast to ramp or strut injectors which may not be removed from the flow field if no hydrogen is injected. Moreover, the injected hydrogen usually acts as a coolant for the strut. Alternative to physical ramp injectors are aero ramps [28] which have a similar physical behavior but lower pressure losses [29]. Aero ramps are multi-hole transverse injectors which induce pairs of counter-rotating vortices to improve mixing and fuel penetration. If strut injectors are used, usually all or most of the fuel is injected in main flow direction. This is possible without the induction of strong shock waves. Moreover, additional momentum is added by parallel fuel injection increasing the engine thrust. This may become important at high flight Mach numbers (10-15) [30]. Due to the limited mixing capabilities of parallel high speed streams, techniques for mixing enhancement are required. This can be achieved either by the use of shock waves [31,32] or by creation of stream wise vorticity. Stream wise vortices may be induced by favorable chosen strut geometry.

Hydrogen should be injected in such a way that a good mixing is achieved over a short length resulting in a homogeneous temperature distribution. Local temperature peaks have to be avoided as to keep dissociation losses and nitrogen oxides low. An important issue at low flight Mach numbers of a scramjet is auto ignition. Due to relatively low air static temperatures this may become a problem for axial strut injectors which only induce weak shock waves and small recirculation zones down stream of the strut. Thus the advantage of avoiding normal shock waves may cause problems for a stable ignition. Four different modes of combustion may be distinguished for strut injectors:

- A stable combustion where the flame is (attached) anchored directly downstream of the strut,

- A stable combustion with a lifted flame which may be stabilized by shock waves and/or a subsonic zone,

- Blow-off of the flame due to unfavorable thermodynamic conditions or bad mixing,

- Thermal choking where the heat release is too high, the flame is moving upstream, and a normal shock causes subsonic flow in the combustor. The subsequent high temperatures usually will cause damage to the strut.

The last two modes have to be avoided and the second one usually reacts sensitive to changes of the inflow conditions. At low flight Mach numbers $(\mathrm{Ma} \approx 7-8)$ and therefore low total temperatures $\left(\mathrm{T}_{0}=1200-1700 \mathrm{~K}\right)$ attached or detached flames are possible [33]. In both cases combustion (at least partially) takes place in subsonic regions. Pure supersonic combustion is obtained at higher flight Mach numbers (Ma $>$ 8 ). The present paper deals with combustor inlet conditions which correspond to the low flight Mach number range.

\section{LITERATURE REVIEW}

Shigeru Aso et.al [1] worked on the topic of "Fundamental study of supersonic combustion in pure air flow with use of shock tunnel", and their findings are - The increase of injection pressure generated strong bow shock, resulting in the pressure loses. The shock generator is an effective method to accelerate the combustion. The increase of the injection total pressure raises the penetration of fuel; thus, the reaction zone expands to the center of flow field. K.M.Pandey and Siva Sakthivel.T[15] worked on the topic of "Recent Advances in Scramjet Fuel Injection - A Review", and their findings are - Fuel injection techniques into scramjet engines are a field that is still developing today. The fuel that is used by scramjets is usually either a liquid or a gas. The fuel and air need to be mixed to approximately stoichiometric proportions for efficient combustion to take place. The main problem of scramjet fuel injection is that the airflow is quite fast, meaning that there is minimal time for the fuel to mix with the air and ignite to produce thrust (essentially milliseconds).Hydrogen is the main fuel used for combustion. Hydrocarbons present more of a challenge compared to hydrogen due to the longer ignition delay and the requirement for more advanced mixing techniques. Enhancing the mixing, and thus reducing the combustor length, is an important aspect in designing scramjet engines. There are number of techniques used today for fuel injection into scramjet engines.

Kyung Moo Kim et.al [2] worked on the topic of "Numerical study on supersonic combustion with cavity-based fuel injection", and their findings are - When the wall angle of cavity increases, the combustion efficiency is improved, but total pressure loss increased. When the offset ratio of upper to downstream depth of the cavity increases, the combustion efficiency as well as the total pressure loss decreases. Yuan shengxue [3] worked on the topic of "supersonic combustion", and his findings are - The calculation of deflagration in supersonic flow shows that the entropy increment and the total pressure loss of the combustion products may decrease with the increase of combustion velocity. The oblique detonation wave angle may not be controlled by the wedge angle under weak under driven solution conditions and be determined only by combustion velocity. Gruenig and F. Mayinger [4] worked on the topic of "Supersonic combustion of kerosene/ $\mathrm{h}_{2}$-mixtures in a model Scramjet combustor", and their findings are - The necessary temperature level is partly achieved by the oblique shock waves in the supersonic flow with increasing combustor area ratio. K. Kumaran and V. Babu [5] worked on the topic of "Investigation of the effect of chemistry models on the numerical predictions of the supersonic combustion of hydrogen", and their findings are Multi step chemistry predicts higher and wider spread heat release than what is predicted by single step chemistry. The single step chemistry model is capable of predicting the overall performance parameters with considerably less computational cost. A better tradeoff between thrust augmentation and combustion efficiency can be achieved through staged combustion.

T. Cain and C. Walton [6] worked on the topic of "review of experiments on ignition and Flame holding in supersonic flow", and their findings are - Low combustor entry temperature is desirable /essential due to intake and nozzle limitations. Hydrogen and hydrocarbon the optimum temperature /pressures are in regions in which ignition delay is very sensitive to temperature, varying from $0.1 \mathrm{~ms}$ 
to $>>10 \mathrm{~ms}$. At low Mach number and static temperatures but at these conditions combustion results in free subsonic regions with very high turbulence. Chemical initiators such as silane, fluorine and OTTO can be used but there are penalties in specific impulse, system complexity and handling hazards. G. Yu, J.G. Li, J.R. Zhao, et al. [7] worked on the topic of "An experimental study of kerosene combustion in a supersonic model combustor using effervescent atomization", and their findings are - The smaller kerosene droplet having higher combustion efficiency. A local high temperature radical pool in the cavity is crucial in promoting the initiation and the subsequent flame holding of the kerosene combustion in a supersonic combustor. A. R. Srikrishnan and j. Kurian et.al. [8] worked on the topic of "An Experimental Investigation of Thermal Mixing and Combustion in Supersonic Flows", and their findings are - A petal nozzle can achieve nearly uniform temperature and momentum fields by using mixing duct. The petal nozzle also results in better combustion, when it is used to inject the fuel-rich gases into a supersonic combustor. Temperature and pressure rises were measured and the supersonic combustion efficiency was found to be of the order of $60 \%$. The performance of a conventional conical nozzle was found to be much inferior to that of the petal nozzle under identical conditions. M Deepu [9] worked on the topic of "Recent Advances in Experimental and Numerical Analysis of Scramjet Combustor Flow Fields", and his findings are - Increase in jet to free stream momentum flux ratio will result in the increase of jet penetration to free stream for all kinds of jets. Injector orientation plays an important role in the strength of the bow shock, with the shocks created by oblique injector being substantially weak compared to transverse injector. S. Zakrzewski and Milton [10] worked on the topic of "Supersonic liquid fuel jets injected into quiescent air", and their findings are - Supersonic liquid jets $M=1.8$ develops from a flat front to a rounded bow within some $10 \mathrm{~mm} \mathrm{M}=$ 5.2 , the bow shape is more pointed and shows signs of an oscillation from more to less pointed.

\section{GOVERNING EQUATIONS}

The advantage of employing the complete Navier-Stokes equations extends not only to the investigations that can be carried out on a wide range of flight conditions and geometries, but also in the process the location of shock wave, as well as the physical characteristics of the shock layer, can be precisely determined. We begin by describing the three-dimensional forms of the Navier-Stokes equations below. Note that the two-dimensional forms are just simplification of the governing equations in the three dimensions by the omission of the component variables in one of the co-ordinate directions. Neglecting the presence of body forces and volumetric heating, the three-dimensional Navier-Stokes equations are derived as

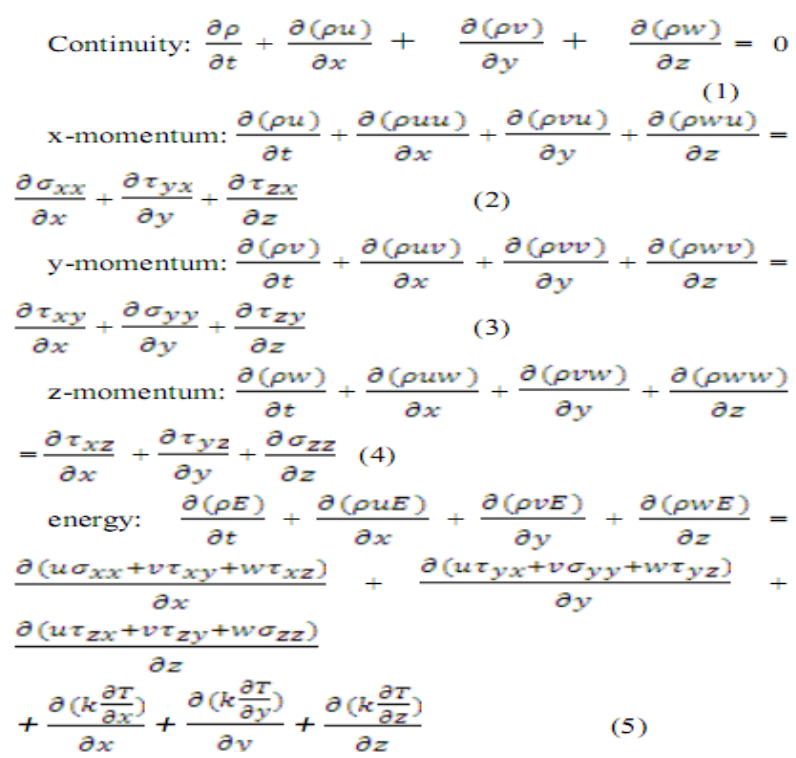

\section{DLR SCRAMJET COMBUSTOR AND COMPUTATIONAL SETUP DETAILS}

In this analysis we are taking same DLR scramjet combustor but strut injection dimension and way of injection is changed from experimental work. A schematic of the DLR (German Aerospace centre) scramjet experimental facility, [11-14], is presented in Fig. 1. Preheated air is expanded through a Laval nozzle and enters the combustor section at $\mathrm{Ma}=2.0$. The combustor has a width of $40 \mathrm{~mm}$ and a height of $50 \mathrm{~mm}$ at the entrance and a divergence angle of the upper channel wall of three degrees to compensate for the expansion of the boundary layer. A planer wedge shaped strut is placed in the combustion chamber downstream of the nozzle. Just downstream of the nozzle the height of the 32 $\mathrm{mm}$ long strut is $0.295 \mathrm{~mm}$. along the first $100 \mathrm{~mm}$ downstream of the nozzle, the side walls and the upper wall are made from quartz glass to allow optical access and to minimize the reflection of scattered light on the wall opposite the observation window. Hydrogen $\left(\mathrm{H}_{2}\right)$ is injected at $\mathrm{Ma}=$ 1.0 through a planer strut injector with diameter of $0.295 \mathrm{~mm}$, in the strut base. Typical mass flows in the experiments were varied between 1.0 and $1.5 \mathrm{~kg} / \mathrm{s}$ for the air and between 1.5 and $4.0 \mathrm{~g} / \mathrm{s}$ for $\mathrm{H}_{2}$, which correspond to equivalence ratios between 0.034 and 0.136 , respectively. The hydrogen is injected at ambient temperature and pressure, i.e. at $\mathrm{T}=250$ $\mathrm{K}$ and $\mathrm{p}=10^{5} \mathrm{~Pa}$, whereas the air was injected at $\mathrm{T}=340 \mathrm{~K}$ and $\mathrm{p}=10^{5} \mathrm{~Pa}$.

\section{0}

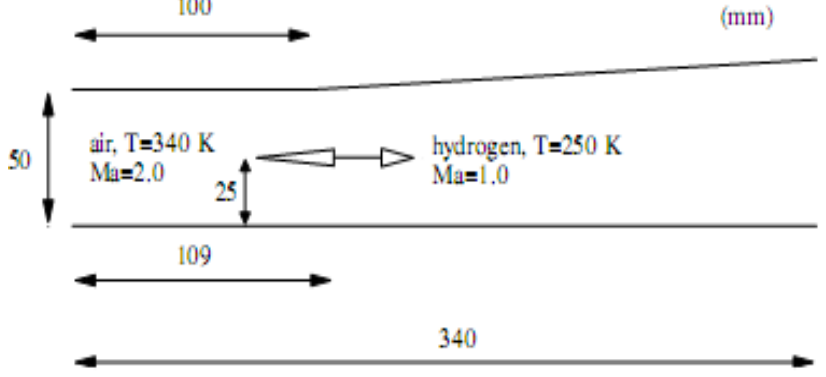

Figure 1 Schematic of the supersonic combustion chamber. 


\section{A.Gambit modelling of 3D Combustion Chamber and Planer Strut Injector}

In the computational configuration same DLR scramjet combustor, strut height are taken and length of the struts are same as experimental one but the injecting the fuel is changed from circular injection to planer injection and operating conditions are same as Experimental one .

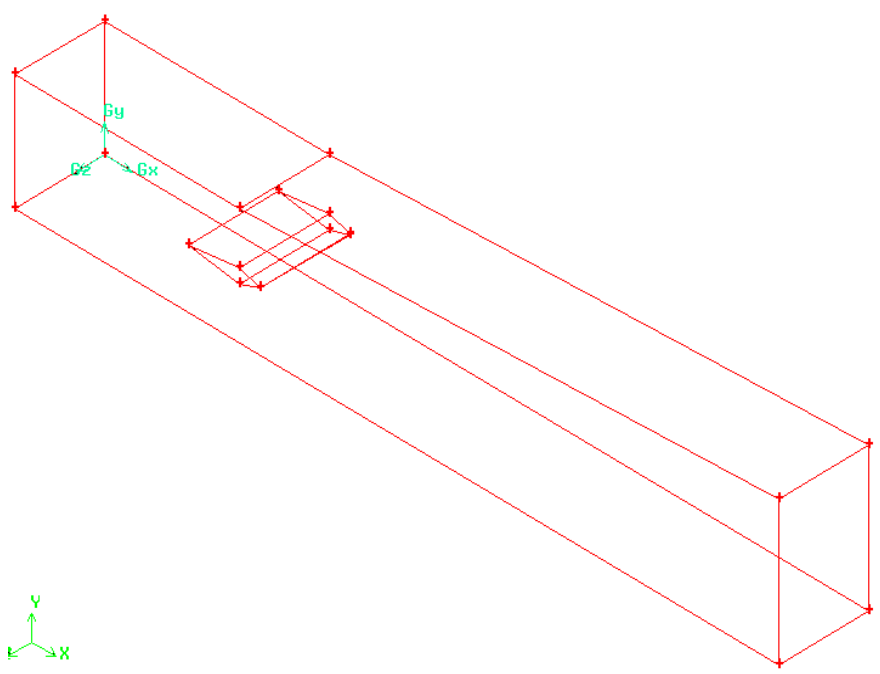

Figure- 2, 3D gambit modelling of DLR Scramjet Combustion Chamber and planer strut injector

\section{B. 3D Planer strut injector}

A wedge-shaped strut is placed in the combustion chamber downstream of the nozzle. The height of the $32 \mathrm{~mm}$ long strut is $0.295 \mathrm{~mm}$ and mass flow rate of strut is 1.5 to $4.0 \mathrm{~g} / \mathrm{s}$.

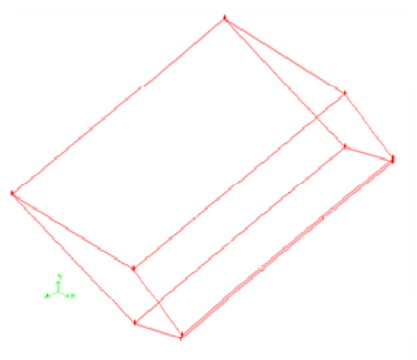

(a) ] konetric view

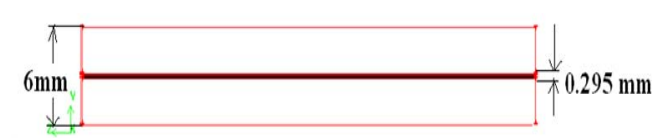

(c) $\mathrm{X}$ - V'ierr

Figure- 3, 3D wedge shaped planer strut injector

\section{BOUNDARY CONDITIONS}

In the present study three different types of boundaries are applied: inflow, outflow and fixed walls. The flow fields under consideration here are supersonic. According to the theory of characteristics all variables are prescribed at inflow boundaries, i.e. Dirichlet boundary conditions, and Neumann boundary conditions are used for all variables at outflow boundaries. At fixed walls the no slip condition are applied. All computations are initialized with the state of the incoming air.
TABLE I: INFLOW CONDITIONS Of THE AIR STREAM AND THE HYdROGEN JET.

\begin{tabular}{ccc}
\hline Variables & Air & $\mathrm{H}_{2}$ \\
\hline$M a$ & 2.0 & 1.0 \\
$u(\mathrm{~m} / \mathrm{s})$ & 730 & 1200 \\
$T(\mathrm{~K})$ & 340 & 250 \\
$P(\mathrm{~Pa})$ & 101325 & 101325 \\
$\rho\left(\mathrm{kg} / \mathrm{m}^{3}\right)$ & 1.002 & 0.097 \\
$Y_{\mathrm{O}_{2}}$ & 0.232 & 0 \\
$Y_{\mathrm{N}_{2}}$ & 0.736 & 0 \\
$Y_{\mathrm{H}_{2} \mathrm{O}}$ & 0.032 & 0 \\
$Y_{\mathrm{H}_{2}}$ & 0 & 1 \\
Mass flow rate $(\mathrm{kg} / \mathrm{s})$ & 1.5 & 0.0015 to 0.004 \\
\hline
\end{tabular}

\section{A. Approximations and Idealizations}

- The flow is considered to be in steady state

- The gas is compressible, obeying the ideal gas laws.

\section{RESULTS AND DISCUSSIONS}

\section{A. Hydrogen injection without combustion}

In this section the cold flow (mixing) without combustion is investigated using $\mathrm{k}-\varepsilon$ model. Inert $\mathrm{H}_{2}$ injection adds significant complexity to the flow in the scramjet combustor since $\mathrm{H}_{2}$ has a considerably lower molar mass than air, which makes mixing an important process in establishing the conditions for scramjet combustion. Figure 4 shows the grid after several adoptions and the computed density distribution.
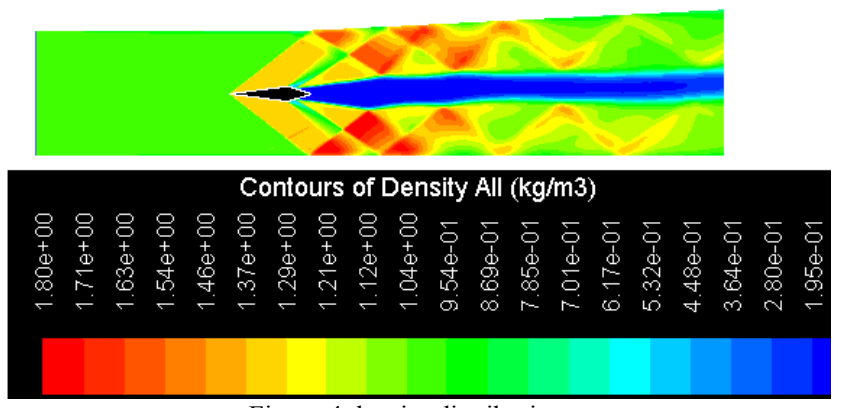

Figure 4 density distribution

With inert $\mathrm{H}_{2}$ injection, oblique shocks are formed at the tip of the wedge that is later reflected by the upper and lower walls. At the upper and lower walls, the boundary layer is affected, at least locally, by the reflected oblique shocks. The boundary layer on the wedge surface separates at the base and a shear layer is formed. This shear layer is naturally unstable and is therefore prone to break-up and develops into Kelvin-Helmholtz (KH) structures and because of the one-sided divergent channel the upper reflecting shock hits the $\mathrm{H}_{2}$ filled wake further downstream than the lower shock, causing an asymmetric flow field through which the $\mathrm{KH}$ modes are amplified. It is important to notice that compressibility leads to reduced shear layer growth, affecting 
the formation and subsequent break-up of large coherent structures. In addition, the reflected shock waves are deflected by the hydrogen jets. After some distance the flow in the wake of the wedge is accelerated back to supersonic speed and the subsequent shocks pass through the accelerating wake.

\section{B. Hydrogen injection with combustion}

Mixing of fuel and air is described in the previous section, it forms a combustible mixture, which is ignited, leading in turn to the combustion of the fuel. The exothermcity resulting from the chemical reactions will likely alter the flow field due to density and temperature changes. Figure 5 shows the combustion by means of a velocity, blue streamlines representing the hydrogen injection and pressure gradients for the shocks.

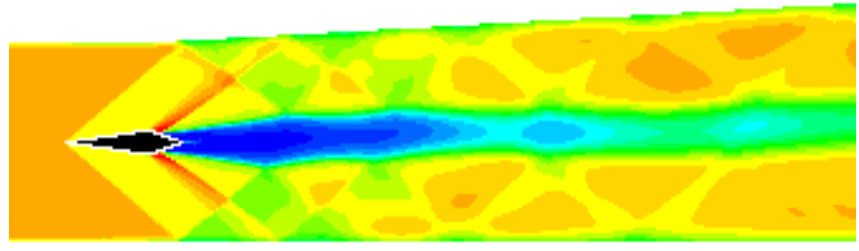

Figure 5 Scramjet combustion

Due to combustion the recirculation region behind the wedge becomes larger as compared to mixing case and it acts as a flame holder for the hydrogen diffusion flame. It is also evident from the above image that the combustion affects the flow field significantly. The leading edge shock reflected off the upper and lower combustor walls facilitates the on setting of combustion when it hits the wake in a region where large portions of the injected fuel have been mixed up with the air. After its first encounter with the flame the leading edge shock is drastically weakened and the characteristic shock wave pattern of the cold flow cases is almost gone. The recompression shocks at the upper and lower wedge corners become much weaker than mixing Case. The shear layers at the base of the wedge becomes more pronounced with combustion due to the fact that continuous ignition occurs within these shear layers. Ignition in turn, is made possible by the rapid advection mixing of fuel and air in the shear layers between the wake and the free stream air. Figure6 shows the shear layer formation in the combustor.

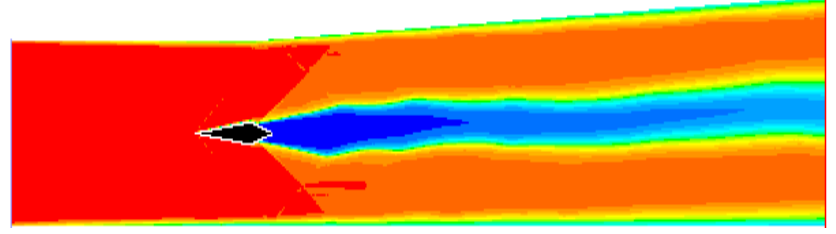

Figure 6 shear layer formation

\section{Static pressure}

The static pressure variation in the combustor showed in figure 7,8 and 9 . From the figure 7 it is clear that at the entrance static pressure is 1 bar, it is increased to 1.7 bar at the centre of the combustor, it is due to reflection of shockwaves after some distances it came to 1.04bar.figure 17 shows the variation of pressure in the top and bottom side of the combustion chamber, it is clear that upto the distance of
$0.77 \mathrm{~m}$ the pressure is constant as a given pressure, after that it is increased to 2.21 bar in bottom wall and 2.01 bar in top wall. Figure 18 shows the pressure variation in the interior of the combustor and over the strut.

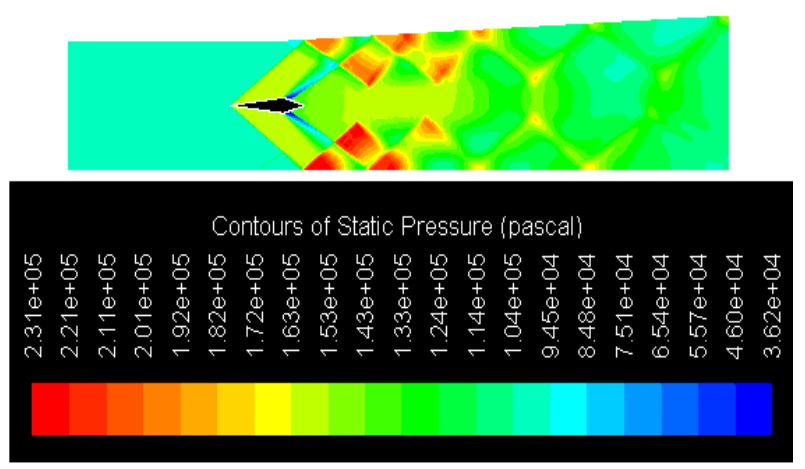

Figure 7 static pressure contours

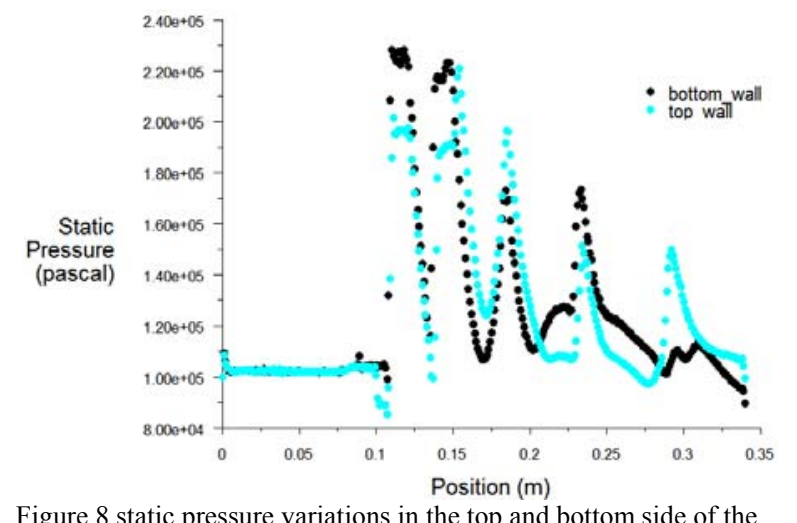

Figure 8 static pressure variations in the top and bottom side of the combustion chamber

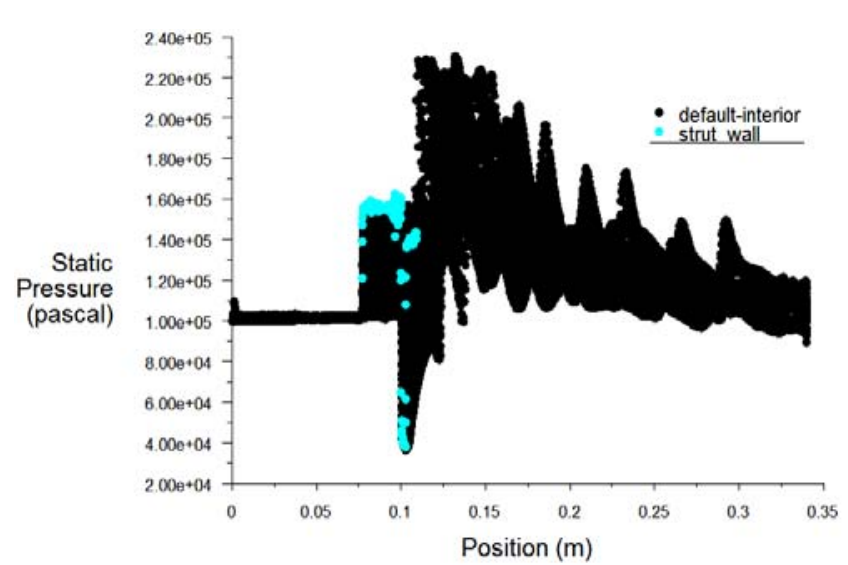

Figure 9 static pressure variations in the interior of the combustion chamber and in the strut

\section{Static Temperature}

The static temperature variation in the combustor given in figure 10,11and12. Figure 10 shows that temperature is constant upto $109 \mathrm{~mm}$ in $\mathrm{x}$ direction, after that it is increasing gradually to maximum of $2870 \mathrm{k}$ at the point of $\mathrm{x}=245 \mathrm{~mm}$. Figure 11 shows the temperature variation in the top and bottom side of the combustion chamber, at the top wall maximum temperature is $590 \mathrm{k}$ at the bottom side it is maximum of $540 \mathrm{k}$ and figure 12 shows the temperature variation in the interior of the combustor. 


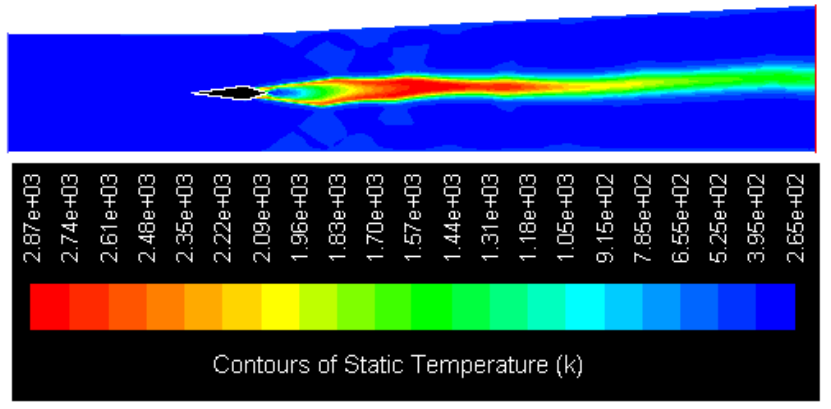

Figure 10 static temperature contours

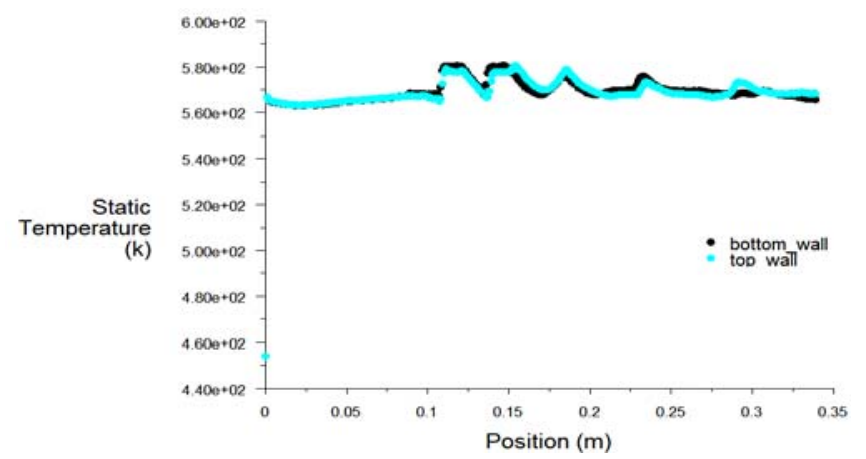

Figure 11 static temperature variations in the top and bottom side of the combustion chamber

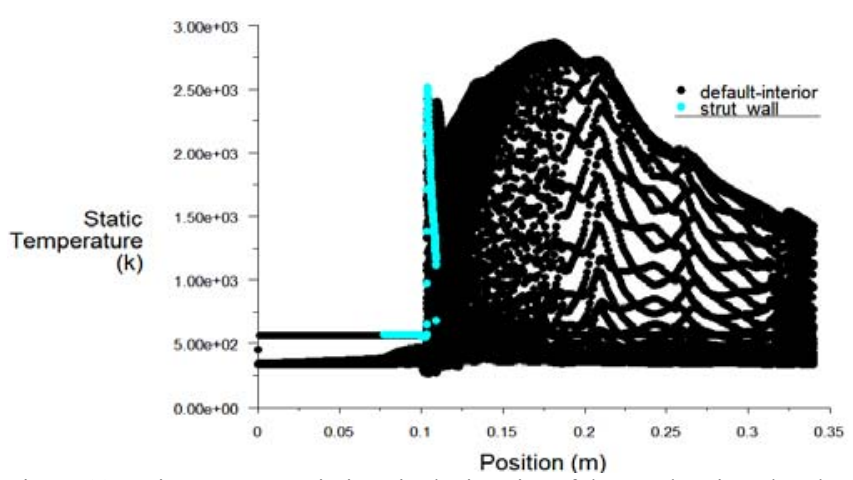

Figure 12 static pressure variations in the interior of the combustion chamber and over the strut

\section{Mach number and Mass fraction of $\mathrm{H}_{2} \mathrm{O}$}

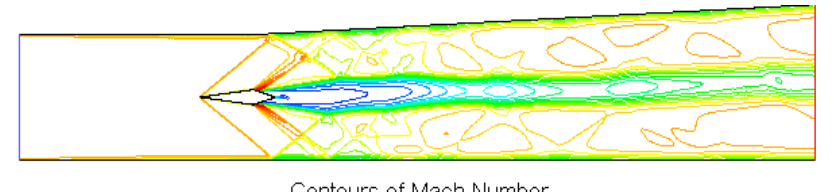

Contours of Mach Number
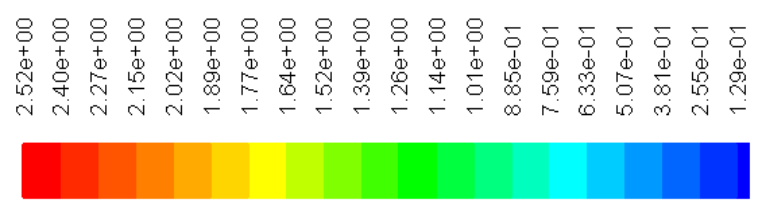

Figure 13 contours of Mach number

Figure 13, 14 are giving the details about how the Mach number variation is taking place inside the Combustion chamber, air is entering at Mach number 2 it is constant up to $\mathrm{X}=77 \mathrm{~mm}$ after that it is started Decreasing to 0.3 it happened due to Shape of the Strut, this subsonic region acting as flame holder for combustion. After some distances speed of the flame become Supersonic. Figure 15 and 16 are giving the details about how the Mass fraction of Water is varying in the combustion Chamber and from the figure it is clear that combustion more are less completed before $0.340 \mathrm{~m}$.

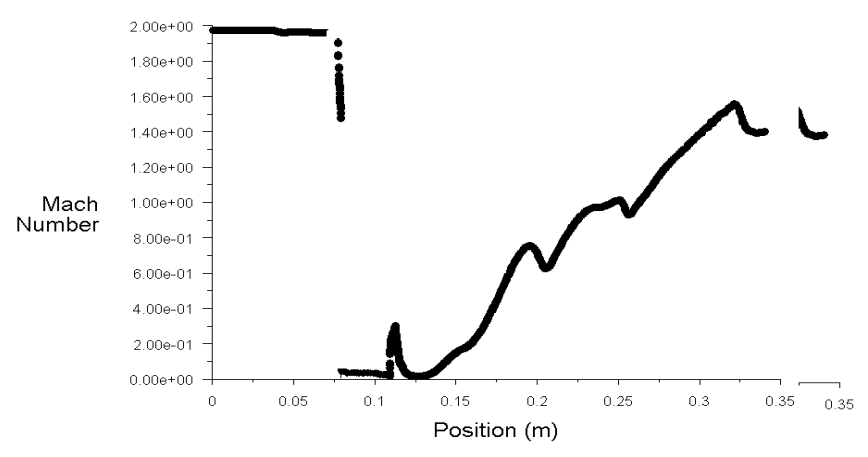

Figure 14 contours of Mach number at $\mathrm{Y}=25$

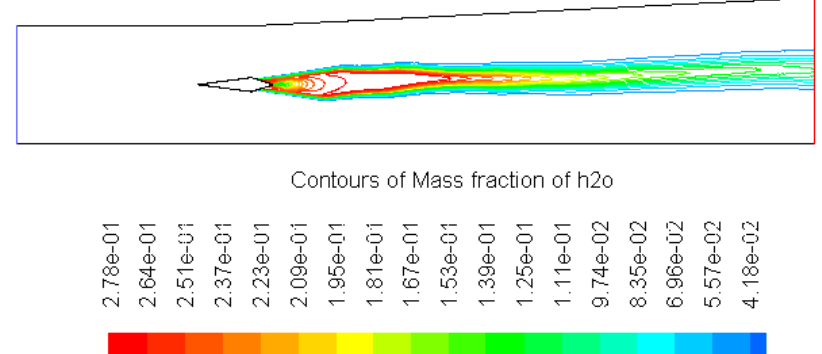

Figure 15 contours of Mass fraction of $\mathrm{H}_{2} \mathrm{O}$

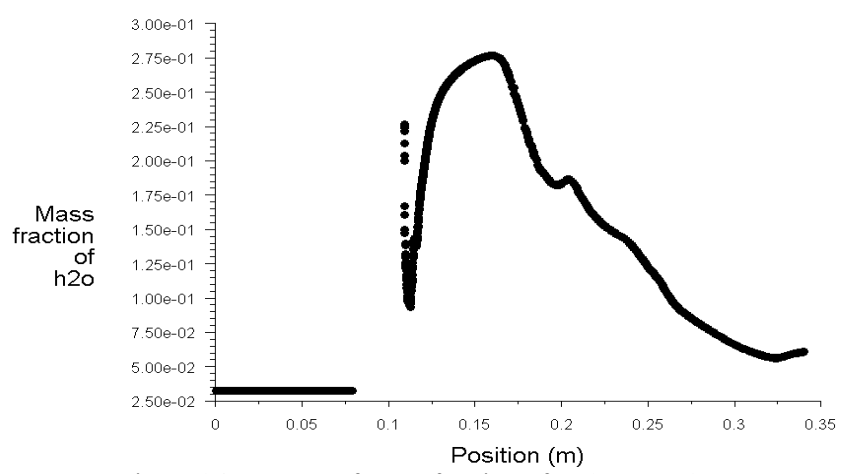

Figure 16 contours of Mass fraction of $\mathrm{H}_{2} \mathrm{O}$ at $\mathrm{Y}=25$

\section{CONCLUSION}

In this paper, in order to investigate the flame holding mechanism of the planer strut in supersonic flow, the two-dimensional coupled implicit RANS equations, the standard $\mathrm{k}-\varepsilon$ turbulence model and the finite-rate/eddy-dissipation reaction model are introduced to simulate the flow field of the hydrogen fueled scramjet combustor with a strut flame holder under different conditions, namely the cold flow and the engine ignition. We observe the following:

- The numerical method employed in this paper can be used to accurately investigate the flow field of the scramjet combustor with planer strut flame holder, and capture the shock wave system reasonably.

- The static pressure of the case under the engine ignition condition is much higher than that of the case under the cold flow condition due to the intense combustion process. 
- There are three obvious pressure rises on the top and bottom walls of the scramjet combustor because of the impingement of the reflected shock wave or the expansion wave on the walls. This illustrates that there exists the complex shock wave/shock wave interaction and the separation due to the interaction of the boundary layer and the oblique shock wave.

\section{ACKNOWLEDGEMENT}

The authors acknowledge the financial help provided by AICTE from the project AICTE: 8023/RID/BOIII/NCP(21) 2007-2008 . The Project id at IIT Guwahati is ME/P/USD/4.

\section{REFERENCES}

[1] 1] Shigeru Aso, ArifNur Hakim, Shingo Miyamoto, Kei Inoue and Yasuhiro Tani, "Fundamental study of supersonic combustion in pure air flow with use of shock tunnel", Department of Aeronautics and Astronautics, Kyushu University, Japan, Acta Astronautica, vol 57, 2005 , pp. $384-389$.

[2] Kyung Moo Kim 1, Seung Wook Baek and Cho Young Han, "Numerical study on supersonic combustion with cavity-based fuel injection", International Journal of Heat and Mass Transfer, vol 47, 2004, pp.271-286.

[3] yuan Shengxue, "supersonic combustion", vol. 42, no. 2, science in china (Series A), February 1999,

[4] Gruenig and f. Mayinger, "supersonic combustion of erosene/h2-mixtures in a model scramjet combustor", institute for thermodynamics, technical university Munich, and d-85747.

[5] K. Kumaran and V. Babu, "Investigation of the effect of chemistry models on the numerical predictions of the supersonic combustion of hydrogen", Combustion and Flame, vol 156, 2009, pp.826-841.

[6] T. Cain and C. Walton "review of experiments on ignition and flame holding in supersonic flow" Published by the America Institute of Aeronautics and Astronautics, RTO-TR-AVT-007-V2.

[7] Yu, J.G. Li, J.R. Zhao, L.J. Yue, X.Y. Chang and C.-J. Sung "An experimental study of kerosene combustion in a supersonic model combustor using effervescent atomization", Proceedings of the Combustion Institute, vol 30, 2005, pp. 2859-2866.

[8] R. Srikrishnan, j. Kurian and v. Sriramulu "an experimental investigation of thermal mixing and combustion in supersonic flows", combustion and flame, vol 107, 1996, pp.464-474.

[9] M Deepu "Recent Advances in Experimental and Numerical Analysis of Scramjet Combustor Flow Fields", Vol. 88, May 2007.

[10] S. Zakrzewski and Milton "Supersonic liquid fuel jets injected into quiescent air", International Journal of Heat and Fluid Flow, vol 25, 2004, pp.833-840.

[11] M. Oschwald, R. Guerra and W. Waidmann, "International Symposium on Special Topics in Chemical Properties", May 10-14,Scheveningen, 1993, pp. 498-503.

[12] W. Waidmann, F. Alff, U. Brummund, M. Bohm,W. Clauss, M. Oschwald, in: DGLR Jahrestagung, Erlangen, 1994, pp. 629-638.

[13] W. Waidmann, U. Brummund, J. Nuding, " ${ }^{\text {th }}$ International Symposium on Transport Phenomena in Comb", July 16-20, San Francisco, USA, 1995, pp. 1473-1484.

[14] W. Waidmann, F. Alff, U. Brummund, M. Bohm,W. Clauss, M. Oschwald, Space Technology, vol 15, 1995, pp.421-429.

[15] K.M.Pandey and T.Sivasakthivel, "Recent Advances in Scramjet Fuel Injection - A Review," International Journal of Chemical Engineering and Applications vol. 1, no. 4, pp. 294-301, 2010.

[16] Glawe, M. Samimiy, A. Nejad, T. Cheng, Effects of nozzle geometry on parallel injection from base of an extended strut into supersonic flow, AIAA paper 95-0522, 1995.

[17] D. Papamoschou, Analysis of partially mixed supersonic ejector, Journal of Propulsion and Power 12 (1996) 736-741.

[18] J. Belanger, H. Hornung, Transverse jet mixing and combustion experiments in hypervelocity flows, Journal of Propulsion and Power 12 (1996) 186-192.

[19] A. Gardner, K. Hannemann, J. Steelant, A. Paull, Ground testing of the hyshot supersonic combustion experiment in heg and comparison with flight data, AIAA paper 2004-3345, 2004
[20] T. Mitani, T. Kouchi, Flame structures and combustion efficiency computed for a Mach 6 scramjet engine, Combustion and Flame 142 (2005) 187-196

[21] I. Waitz, F. Marble, E. Zukoski, Investigation of a contoured wall injector for hypervelocity mixing augmentation, AIAA Journal 31 (1993) 1014-1021.

[22] D. Riggins, Thrust losses in hypersonic engines, part 2: Applications, Journal of Propulsion and Power 13 (1997) 288-295.

[23] R. Baurle, R. Fuller, J. White, T. Chen, M. Gruber, A. Nejad, An investigation of advanced fuel injection schemes for scramjet combustion, AIAA paper 98-0937, 1998.

[24] Strickland, T. Selerland, A.R. Karagozian, Numerical simulation of a lobed fuel injector, Journal of Propulsion and Power 10 (1998) 2950-2964.

[25] Charyulu, J. Kurian, P. Venugopalan, V. Sriamulu, Experimental study on mixing enhancement in two dimensional supersonic flow, Experiments in Fluids 24 (1998) 340-346.

[26] T. Sunami, M. Wendt, M. Nishioka, Supersonic mixing and combustion control using stream wise vorticity, AIAA paper 98-3271, 1998.

[27] Riggins, C. McClinton, R. Rogers, R. Bittner, Investigation of scramjet injection strategies for high Mach number flows, Journal of Propulsion and Power 11 (1995) 409-418.

[28] Cox, R. Fuller, J. Schetz, Vortical interactions generated by an injector array to enhance mixing in supersonic flow, AIAA paper 94-0708, 1994.

[29] L.Maddalena, T. Campioli, J. Schetz, Experimental and computational investigation of light-gas injectors in Mach 4.0 crossflow, Journal of Propulsion and Power 22 (2006) 1035-2006.

[30] T. Sunami, K. Itoh, T. Komuro, K. Sato, Effects of streamwise vortices on scramjet combustion at Mach 8-15 flight enthalpies - an experimental study in hiest, ISABE paper 2005-1028, 2005.

[31] E. Fernando, S. Menon, Mixing enhancement in compressible mixing layers: An experimental study, AIAA Journal 31 (1993) 278-285.

[32] J.-H. Kim, Y. Yoon, I.-S. Jeung, H. Huh, J.-Y. Choi, Numerical study ofmixing enhancement by shock waves in model scramjet engine, AIAA Journal 41 (2003) 1074-1080.

[33] T. Sunami, A. Murakami, M. Nishioka, Mixing and combustion control strategies for efficient scramjet operation in wind range of flight Mach numbers, AIAA paper 2002-5116, 2002.

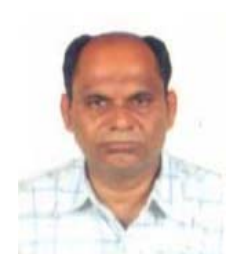

Dr. K.M.Pandey did his $\mathrm{PhD}$ in Mechanical Engineering in 1994 from IIT Kanpur. He has published and presented 170 papers in International \& National Conferences and Journals. Currently he is working as Professor of the Mechanical .Engineering Department, National Institute of Technology, Silchar, Assam, India..He also served the department in the capacity of head from July 07 to 13 July 2010 . He has also worked as faculty consultant in Colombo Plan Staff College, Manila, Philippines as seconded faculty from Government of India. His research interest areas are the following; Combustion, High Speed Flows, Technical Education, Fuzzy Logic and Neural Networks , Heat Transfer, Internal Combustion Engines, Human Resource Management, Gas Dynamics and Numerical Simulations in CFD area from Commercial Software's.

Email:kmpandey2001@yahoo.com.

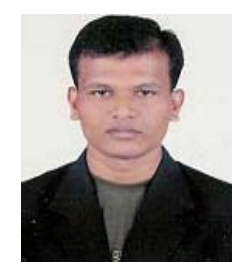

T.Sivasakthivel doing his M.Tech - Thermal Engineering in NIT Silchar from 2009. He has also worked as a Graduate Apprentice in BHEL Trichy from 2008 to 2009. His research interests are CFD, Combustion and Gasification.

Email: sivasakthivel.t@gmailcom 